\title{
PERCEPÇÃO DA QUALIDADE DE SERVIÇOS NA BIBLIOTECA MUNICIPAL MURILO MENDES DE JUIZ DE FORA NA PERSPECTIVA DO USUÁRIO
}

\author{
ANTONIO LUIZ MATTOS DE SOUZA CARDOSO* \\ ROGERIO ZANON DA SILVEIRA** \\ MARCELO CALDERARI MIGUEL ${ }^{* * *}$
}

\begin{abstract}
RESUMO
A percepção de qualidade da comunidade usuária pode ser considerada o início de ciclo de satisfação, formação de imagem e desenvolvimento do serviço no âmbito dos espaços não formais de educação. Assim, o presente artigo pretende analisar a qualidade dos serviços da Biblioteca Municipal Murilo Mendes, de Juiz de Fora, com o intuito de auxiliar a melhoria dos serviços ofertados, averigua a expectativas e as percepções da comunidade usuária em uma biblioteca pública. A amostra é composta por 410 participantes e o diagnóstico é descritivo, quantitativo e do tipo survey. $O$ instrumento de coleta de dados baseia-se em questionário, adaptando Gap Model - Servqual. Os dados foram coletados entre março e maio de 2017 no hall de saída da biblioteca. Os resultados apontam que o instrumento Servqual é uma ferramenta que concilia boas propriedades psicométricas, ou seja, traz à tona um diagnóstico válido e confiável sobre a qualidade dos serviços no âmbito da instituição pesquisada. Entre as considerações, destaca-se que foram encontradas limitações no decorrer da execução deste estudo, recomenda-se o aprofundamento do mesmo e o uso do modelo Servqual.
\end{abstract}

PALAVRAS-CHAVE: Edifícios de biblioteca. Métodos de avaliação - Servqual. Promoção de uso de biblioteca. Qualidade. Usuários da biblioteca.

\begin{abstract}
The quality perception of the user community can be considered as the beginning of a cycle of satisfaction, image formation and service development within non-formal educational spaces. Thus, the present article intends to analyze the quality of the services of the Murilo Mendes Municipal Library of Juiz de Fora city, with the purpose of
\end{abstract}

\footnotetext{
Universidade Federal do Espírito Santo. Professor do Departamento de Biblioteconomia.

${ }^{* *}$ Universidade Federal do Espírito Santo. Prof. Dr. em Administração.

** Universidade Federal do Espírito Santo. Graduação em Biblioteconomia, Ciências Contábeis e Administração.
} 
assisting the improvement of the services offered, ascertain the expectations and perceptions of the user community in a public library. The sample is composed of 410 participants and the diagnosis is descriptive, quantitative and of the survey type. The data collection instrument is based on a questionnaire adapting the Gap Model Servqual. Data were collected between March and May 2017 in the library exit hall. The results indicate that the tangible aspects require improvement in this institution. It is recommended that the Servqual be exploited in multivariate approaches, going to meet the particular aspects of Information Science.

KEYWORDS: Library buildings. Evaluation methods - Servqual. Library use promotion. Quality. Library users.

\section{RESUMEN}

La percepción de calidad de la comunidad usuaria puede ser considerada el inicio del ciclo de satisfacción, formación de imagen y desarrollo del servicio en el ámbito de los espacios no formales de educación. Así el presente artículo pretende analizar la calidad de los servicios de la Biblioteca Municipal Murilo Mendes de Juiz de Fora, con el propósito de auxiliar la mejora de los servicios ofrecidos averigua las expectativas y las percepciones de la comunidad usuaria en una biblioteca pública. La muestra se compone de 410 participantes y el diagnóstico es descriptivo, cuantitativo y del tipo survey. El instrumento de recolección de datos se basa en un cuestionario adaptando Gap Model - Servqual. Los datos fueron recolectados entre marzo y mayo de 2017 en el hall de salida de la biblioteca. Los resultados señalan que los aspectos tangibles requieren mejoras en esta institución. Se recomienda que el Servqual sea envuelto en enfoques multivariados, yendo al encuentro de los aspectos particulares a la Ciencia de la Información.

PALABRAS CLAVE: Edificios de biblioteca. Métodos de evaluación - Servqual. Promoción de uso de biblioteca. Calidad. Usuarios de la biblioteca.

\section{INTERAÇÃO... O 'OLHAR QUE PENETRA NAS CAMADAS DO MUNDO'}

"Pertenço à categoria não muito numerosa dos que se interessam igualmente pelo finito e pelo infinito. Atraem-me a variedade das coisas, a migração das ideias, o giro das imagens, a pluralidade de sentido de qualquer fato, a diversidade dos caracteres e temperamentos, as dissonâncias da história. Sou contemporâneo e partícipe dos tempos [...]" (MENDES, 1994, p. 45-46).

\section{A 'biblioteca' é considera uma unidade disseminadora de informação que "interage com as tecnologias e pessoas que a}


cercam" (CALDAS; SILVA, 2016, p. 32). Partindo desse conceito de interação, entendemos que tal termo perpassa por diferentes estruturas da vida social e se destaca nas esferas organizacional e informacional - bidirecionando práticas específicas nesses contextos.

Historicamente, o estudo das interações sociais provocou privilegiadamente os cenários da Comunicação Social, Administração, Antropologia, Psicologia e Sociologia. Atualmente, as referências ao termo interagente começam a ser encontradas em trabalhos das mais diversas naturezas e em múltiplas áreas do conhecimento, circundando também o universo da Biblioteconomia (CORRÊA, 2014) em variadas formas de estudos e abordagens.

Primo e Cassol (1999, p. 66) reportam que é preciso "valorizar a bidirecionalidade, a comunicação contextualizada, enfim, aquilo que ocorre entre os interagentes e a evolução inventiva e criativa dos relacionamentos". Sobre a interação, neste caso, a interação humana, é plausível considerá-la um modelo segundo o qual os interagentes percebem trocas, negociam e significam 0 ato informacional, por isso a escolha desse termo - para identificar, protagonizar e empoderar as pessoas que utilizam a biblioteca e centros de informação.

A presente pesquisa aborda a seguinte problemática: quais as percepções e expectativas dos interagentes da Biblioteca Municipal Murilo Mendes (BMMM) sobre o serviço ofertado? Este estudo averigua a qualidade dos serviços prestados na BMMM, enfocando a satisfação e importância da qualidade dos serviços da biblioteca na concepção dos diversos interagentes - a comunidade usuária dessa instituição.

A metodologia faz uma adaptação da abordagem de Parasuraman, Zeithaml e Berry (1985), envolvendo a métrica Servqual. Busca diagnosticar a qualidade dos serviços prestados e captar norteadores imprescindíveis à tomada de decisão organizacional. Em suma, esta pesquisa apresenta uma perspectiva utilitária da abordagem teórico-metodológica Servqual como um instrumento capaz de aferir a relevância das dimensões da qualidade em espaços formais ou não de educação.

Ao encontro dessa constatação, lembramos que Tomaél et al. (2006) assinalam que a inteligência competitiva gera informações que possibilitam valor aos produtos, processos e serviços existentes na organização, além de dar um suporte à criação de estratégias competitivas, sustentando o processo de inovação. Todavia, no contexto da biblioteca pública, vem à tona também a questão da qualidade: Como se avaliar um serviço? Qual imagem, 
funcionalidade e missão a instituição propaga? Como os interagentes posicionam os serviços prestados?

Com esse painel, adotamos a abordagem teórico-metodológica Servqual (Service Quality Gap Analysis), a qual aponta que quem define se um serviço tem qualidade ou não é o interagente - com base nas percepções e expectativas, diante dos referenciais de qualidade. Assim, os referenciais de qualidade (Confiabilidade, Empatia, Garantia, Receptividade e Tangibilidade) entrelaçam-se para constituir dimensões essenciais à prestação de serviços.

Nesse sentido, esta pesquisa buscou avaliar a qualidade do atendimento prestado no âmbito da BMMM provocados por algumas diretrizes, tais como: a) a questão científica - fornecer uma fonte de conhecimento sobre a qualidade dos serviços em bibliotecas públicas; b) a perspectiva sociorganizacional - subsidiar a tomada de decisão e o desenvolvimento de boas práticas (best practices) organizacionais; e c) a proeminência institucional - demarcar o lugar social ocupado pela Biblioteca Pública, a performance e visibilidade dos serviços.

Ressalta-se, ainda, que a biblioteca investigada compreende 'um organismo' que converge seus objetivos em prol dos interagentes, favorecendo o hábito da leitura, disseminando os benefícios das fontes de informação e promovendo um ambiente dialógico-reflexivo. Dessa forma, servir à sociedade com zelo, elevar as práticas de leitura, desenvolver o nível cultural e efetivar a compleição da paz constituem permanente missão que pauta a constituição das bibliotecas públicas.

Este trabalho está estruturado de modo a tratar sequencialmente sobre: o papel da biblioteca pública, a biblioteca municipal de referência; a gestão e qualidade em serviços, determinantes da qualidade e inter-relações com a métrica Servqual. Posteriormente, é descrito a ambiência pesquisada, abordando a metodologia utilizada, os resultados e a discussão referentes à análise dos dados da BMMM como objeto da pesquisa, e, por fim, a conclusão retoma pontos centrais da temática abordada.

\section{2 'VIM PARA SOFRER AS INFLUÊNCIAS DO TEMPO...'}

Percebe-se pela composição muriliana "Vim para sofrer as influências do tempo / E para firmar o princípio eterno de onde vim" (MENDES, 1994, p. 410) uma articulação que circunda a esfera da transformação e existência. Essa provocação poética é o pontapé inicial de reflexão sobre as bibliotecas públicas, e, nos textos a seguir, vamos adentrar nessa questão. 


\subsection{Bibliotecas públicas: núcleo de formação, informação, cultura e lazer}

O Sistema Nacional de Bibliotecas Públicas Brasileiras SNBP descreve que a Biblioteca Pública tem por objetivo atender, por meio do seu acervo e de seus serviços, aos diferentes interesses de leitura e informação da comunidade em que está localizada, colaborando para ampliar o acesso à informação, à leitura e ao livro, constituindo-se um equipamento cultural (SANTOS, 2014).

O SNPB realizou, em 2015, o levantamento dos dados desses equipamentos culturais e identificou 6.057 bibliotecas públicas no Brasil (SNBP, 2015). A referida pesquisa mostrou que $32 \%$ das bibliotecas públicas estão localizadas na Região Sudeste (que possui 1.957 bibliotecas públicas, das quais 1.948 são municipais, sete são estaduais e duas são federais); e, em segundo lugar, a Região Sul do Brasil concentra $21 \%$ das bibliotecas públicas do país (1.293 delas são bibliotecas públicas, das quais, 1.289 são municipais e quatro são estaduais). Logo, os setes estados da federação (região Sul e Sudeste) concentram 53\% (3.250) das bibliotecas públicas no país, e quase cem por cento $(99,60 \%)$ dessas entidades são municipais.

A Biblioteca Pública - porta de acesso local ao conhecimento fornece, conforme aponta o manifesto IFLA/UNESCO (1994), as condições básicas para uma aprendizagem contínua, para uma tomada de decisão independente e para o desenvolvimento cultural dos indivíduos e dos grupos sociais. Mas antes de 'acusar ou enaltecer' a biblioteca pública é necessário, afirmam Bernardino e Suaiden (2011, p. 140), fazer valer as diretrizes do Manifesto da UNESCO com a finalidade de erguer uma biblioteca pública "cada vez mais democrática, acessível e necessária, vinculada e integrada" e "condizente com as necessidades da sociedade da informação".

Bernardino e Suaiden (2011, p. 139) apontam:

Portanto, o papel da biblioteca pública na sociedade da informação será efetivado quando esta estabelecer relações estreitas com a sua comunidade usuária [os interagentes], tendo-a como foco principal de atuação, sendo imprescindível no que se fizer necessário, proporcionando o acesso à informação em qualquer suporte a qualquer pessoa e em qualquer tempo, inserindo sua clientela no processo global permeados pelo acesso às tecnologias da informação e da comunicação. 
O tom desafiador dessa perspectiva também é deparado no estudo de Silveira (2018, p. 165), que assinala para a "Força de representação [...] a Biblioteca é também um espaço onde os conflitos, as contradições, os paradoxos e as distorções de força que perpassam as interações entre os sujeitos e a sociedade se condensam e fazem-se perceptíveis". A biblioteca pública está umbilicalmente ligada àqueles que a organizam, que a fazem viver e, portanto, que emprestam a marca de sua vontade, constituindo-se uma célula viva, ímpar.

Além do espaço de educação, avoca-se à biblioteca pública a responsabilidade de atuar para o lazer. A Declaração Universal dos Direitos Humanos completou setenta anos. O lazer é sinalizado como direito social e Saldanha e Pereira (2016) compreendem que as práticas de lazer em bibliotecas (públicas e escolares) e suas políticas devem ser estudadas por guardar um enorme potencial de transformação crítica do sujeito. Os pesquisadores enfatizam que a biblioteca pode 'competir' expressivamente, como uma alternativa de destaque, entre distintas formas de lazer - para tal é preciso investir, fortalecer $\mathrm{o}$ atendimento, identificar os principais anseios referentes ao lazer, como também antecipar as demandas de transformação 'lançando mão de todo manancial plural' de indivíduos da comunidade e suas linguagens.

De maneira geral, entendemos que a biblioteca como 'serviço de informação' necessita estruturar-se de modo a ofertar informação de alta qualidade, buscando compreender e interpretar as necessidades de informação de seus interagentes, além de averiguar se as necessidades apontadas pelos consulentes foram atendidas de forma efetiva (TRZECIAK, 2009).

\subsection{Biblioteca pública e sua transformação}

A biblioteca municipal de Juiz de Fora foi planejada em 1889 pela Câmara Municipal e a inauguração oficial aconteceu em 28 de dezembro de 1897. Foi instalada, inicialmente, em um pavilhão circunscrito no Parque Halfeld e passou por diversas casas; já em 1982 (com 85 anos), a instituição recebeu o nome de 'Biblioteca Municipal Murilo Mendes' (BMMM) - uma homenagem ao poeta juizforano. A BMMM é considerada uma instituição cultural mais antiga em funcionamento no município, passou por diversas sedes até que, em 1996 (99 anos após sua criação), instala-se, definitivamente, no complexo do Mercado Municipal, ao lado do Centro Cultural Bernardo Mascarenhas, na Praça Antônio Carlos. 
O prédio da fábrica têxtil Bernardo Mascarenhas passou por reformas e adaptações para abrigar o acervo da BMMM. A nova sede BMMM ocupa três andares da antiga fábrica e foi estruturada em seis setores: a) primeiro andar comporta o setor de empréstimo; b) segundo segue o setor administrativo da biblioteca e o setor Louis Braille; e c) no terceiro andar, a seção de 'Memórias' - coleção especial, obras raras, registros de valor histórico sobre a história da Zona da Mata Mineira.

\section{QUADRO 1 - Setores e características da BMMM (Sede)}

\begin{tabular}{|c|c|}
\hline & SETORES DA BIBLIOTECA \\
\hline $\begin{array}{l}\text { Setor de } \\
\text { Referência }\end{array}$ & $\begin{array}{l}\text { - Acervo constituído por enciclopédias, dicionários, livros } \\
\text { didáticos e informativos. } \\
\text { - Horário: segunda a sexta-feira, das } 8 \text { h15 às } 19 \mathrm{~h} 45 \text { e, } \\
\text { aos sábados, das } 8 \text { h15 às } 13 \mathrm{~h} 45 \text {. }\end{array}$ \\
\hline $\begin{array}{l}\text { Setor de } \\
\text { Periódicos }\end{array}$ & $\begin{array}{l}\text { - Acervo constituído por jornais e revistas locais } \\
\text { e nacionais. } \\
\text { - Horário: segunda a sexta-feira, das } 8 \text { h } 15 \text { às } 18 \mathrm{~h} \text { e, aos } \\
\text { sábados, das } 8 \mathrm{~h} 15 \text { às } 13 \mathrm{~h} 45 \text {. }\end{array}$ \\
\hline $\begin{array}{l}\text { Setor Infanto- } \\
\text { juvenil }\end{array}$ & $\begin{array}{l}\text { - Acervo de livros infantis, infanto-juvenis e gibis, espaço } \\
\text { de leitura e recreação. } \\
\text { - Horário: segunda a sexta-feira, das } 8 \text { h15 às } 17 \mathrm{~h}\end{array}$ \\
\hline $\begin{array}{l}\text { Setor de } \\
\text { empréstimo }\end{array}$ & $\begin{array}{l}\text { - Acervo de obras de variada temática, disponíveis para } \\
\text { empréstimo em domicílio. } \\
\text { - Horário: segunda a sexta-feira das } 8 \mathrm{~h} 15 \text { às } 19 \mathrm{~h} 45 \text {. }\end{array}$ \\
\hline Setor Braille & - Horário: segunda a sexta-feira das $8 \mathrm{~h} 15$ às $18 \mathrm{~h} 45$. \\
\hline $\begin{array}{l}\text { Setor de } \\
\text { Memória }\end{array}$ & $\begin{array}{l}\text { - Acervo de periódicos locais \& históricos e a Coleção } \\
\text { Juiz-forana [obras editadas na cidade] } \\
\text { - Horário: segunda a sexta-feira, das } 8 \mathrm{~h} 15 \text { às } 12 \mathrm{~h} \text { e das } \\
14 \mathrm{~h} \text { às } 18 \mathrm{~h} \text {. }\end{array}$ \\
\hline
\end{tabular}

FONTE: Adaptado do site institucional da Prefeitura de Juiz de Fora (PMJF, 2016).

A sede atual da BMMM completou 22 anos em 2018 e a Instituição ainda possui uma organização subsidiária - a Biblioteca Sucursal Delfina Fonseca Lima do Bairro de Benfica - na zona norte de Juiz de Fora, a qual não adentra na esfera da presente análise. Convém destacar que a sucursal foi premiada (Instituto Pró-Livro Retratos da Leitura, 2017) devido ao projeto (Leitores e Mediadores em Ação) que aconchega a comunidade.

Ao longo dos seus mais de 120 anos, constituiu um importante acervo bibliográfico que vem atraindo diversos interagentes e contribuindo para a ampliação da pesquisa e leitura nessa região. Atualmente, a BMMM é gerenciada pela Fundação Cultural Alfredo 
Ferreira Lage (Funalfa) - organização que visa aprimorar o gosto pela leitura e fomenta o despertar cultural na Zona da Mata Mineira - e recebe apoio da Associação de Amigos da Biblioteca Municipal Murilo Mendes (AABIMMM, criada em 2001), que implementa ações para a revitalização dos serviços da Biblioteca.

Com o percurso e apontamentos citados, a Instituição se converte em ponto de referência cultural dos juiz-foranos, não só em função das ações que desenvolve em prol da preservação e difusão da memória da cidade, mas, sobretudo, por sua atuação educacional nas áreas de promoção da leitura, democratização do conhecimento, disseminação da informação e do fomento às artes e ao lazer.

\subsection{Gestão e qualidade em serviços}

Nas últimas décadas, o conceito de qualidade obteve contribuições nos estudos organizacionais, sendo uma das práticas visionária do desenvolvimento sustentável e imprescindível à sobrevivência das organizações. Qualidade é definida por diversos autores e acrescenta-se a concepções específicas em relação à qualidade em serviços, ou seja, a qualidade em serviços deve ser, acima de tudo, aquilo que os clientes percebem, é o que afirma Grönroos (2003).

Por conseguinte, a percepção é algo extremamente subjetivo, faz-se necessário um diagnóstico para entender a qualidade percebida pela clientela e advém da comparação entre o serviço esperado e o serviço percebido (GRÖNROOS, 1984). O modelo conceitual de qualidade postulado por Grönroos (1984; 2003) compreende três componentes: imagem corporativa, qualidade técnica e qualidade funcional. A esfera técnica compreende a entrega do serviço conforme especificado pela organização prestadora, em outras palavras, está relacionada com a tramitação do 'pacote de valor' para a comunidade de usuários. Próximo a essa perspectiva, Neves e Vinagre (2018, p. 16-17) argumentam que consumidor de um serviço é:

[...] o principal juiz na avaliação da sua qualidade. Por isso, qualquer métrica da qualidade de serviço deverá, para ser credível, ancorar-se nas expectativas que o consumidor tem acerca de um serviço [...] [a] Opinião do consumidor e opinião da organização servem de base à definição de um modelo de avaliação da qualidade de serviço, o Gap Model, o qual faz da diferença entre as expectativas do consumidor acerca do serviço e a percepção do serviço recebido, o indicador 
principal da qualidade de serviço [...] Trata-se, por isso, de um modelo complexo, na medida em que a sua operacionalização implica recolher informação de consumidores e dos prestadores do serviço sobre uma diversidade de aspetos relacionado com o desempenho do serviço e ao mesmo tempo rico, porquanto, possibilita recolher informação útil para efeitos de diagnóstico e de intervenção sobre os elementos que mais diretamente contribuem para a qualidade de serviço (NEVES; VINAGRE, 2018, p. 16-17).

Portanto, o aspecto funcional da qualidade é focado na utilização do serviço, nas interações de execução. Neves e Vinagre (2018) reconhecem que a avaliação das expectativas da clientela sobre os serviços possibilita padronizar a atividade na entidade para que a mesma exerça padrões de desempenho e garanta promessas feitas ao seu público, além disso, o diagnostico transparece as relações e evidências físicas - os fatores influenciadores, associados à prestação de um serviço - servindo de base à avaliação final da qualidade de serviço e da própria continuidade da instituição.

\subsection{Dimensões da qualidade e o contexto métrico Servqual}

Dentre os inúmeros instrumentos da qualidade que analisam os serviços, encontra-se a abordagem Servqual. Essa é uma métrica que representa um marco na literatura da área de qualidade em serviços; posteriormente, diversas pesquisas vieram amadurecer as construções científicas em proveito à questão da qualidade (CAMPOS, MIGUEL, CARVALHO, 2018). Campos, Miguel e Carvalho (2018) alertam que a métrica Servqual é uma abordagem de investigação científica que traz algumas contribuições preciosas para o campo das pesquisas em espaços não formais de educação, em particular os estudos que se interessam por situações sociointeracionais, abrangendo o processo de desenvolvimento de novos serviços.

Ainda, verifica-se que há a preocupação de introduzir os atores sociais numa participação ativa e dinâmica no processo de avaliação de serviços, ao mesmo tempo, que a metodologia é capaz de concretizar delineamentos a um rol de estudos organizacionais sobre o que esse público necessita ou deseja. Em suma, a abordagem Servqual inicia-se com o entendimento das determinantes da qualidade em serviço e posterior comparação da distância entre o desejo e o desempenho real alcançado, sendo cinco dimensões essencias abordadas, ou seja, os aspectos tangíveis (tangibles), confiabilidade (reliability), a receptividade a ou 
sensibilidade (responsiveness), a segurança ou garantia (assurance) e a empatia (empathy).

Sobre os constructos mencionados acima, Fitzsimmons e Fitzsimmons (2010) asseveram que:

- Aspectos tangíveis: abrangem as aparências das instalações físicas e as condições do ambiente, como apresentação dos equipamentos, vestimentas dos funcionários, materiais de comunicação e manutenção da limpeza.

- Confiabilidade: aludir à capacidade da empresa de entregar o serviço prometido com confiança e exatidão. Neste aspecto o cliente espera receber o serviço no prazo determinado e sem a presença de erros;

- Receptividade: refere-se à disposição dos funcionários em atender aos clientes e fornecer os serviços prontamente. A empresa deve evitar a espera sem motivo por parte do cliente, mas caso ocorra a falha, a empresa deve buscar solucioná-la com rapidez e profissionalismo;

- Garantia: está associada ao comportamento dos funcionários quanto ao conhecimento da empresa, a cordialidade e a capacidade de transmitir informações para a clientela. Envolve características como respeito e cortesia e a manifestação efetiva do interesse na satisfação do público;

- Empatia: cinge à capacidade da organização em demonstrar atenção personalizada ao cliente. Neste aspecto deve a instituição ratificar sensibilidade e esforço para compreender e atender as necessidades específicas de cada interagente.

As cinco determinantes da qualidade são atributos genéricos do serviço, subdivididas em assertivas, que delineiam o serviço sob o ponto de vista do cliente que irá julgá-lo. A compreensão desses construtos da qualidade em serviços, bem como a comparação entre o que é esperado e o que é percebido, foi o relevante insight para que Parasuraman, Zeithaml e Berry (1985) estruturassem a escala Servqual, tomando como base a perspectiva conceitual das lacunas (gap model) na Qualidade de Serviço e as discrepâncias entre as expectativas e as percepções do desempenho.

A concepção do modelo das lacunas é viabilizada na estrutura a seguir (Figura 1), convém lembrar que diversos pesquisadores constataram que a clientela 'utiliza os mesmos critérios', independentemente do 'tipo de serviço' nas perquisições sobre a qualidade. No entanto, esse diagnóstico métrico envolve 
complexidade de análise e aplicabilidade, e faz-se imprescindível para que idiossincrasias do serviço sejam reconhecidas para que possam ser estreitadas no diagnóstico.

FIGURA 1 - As cinco lacunas na qualidade dos serviços

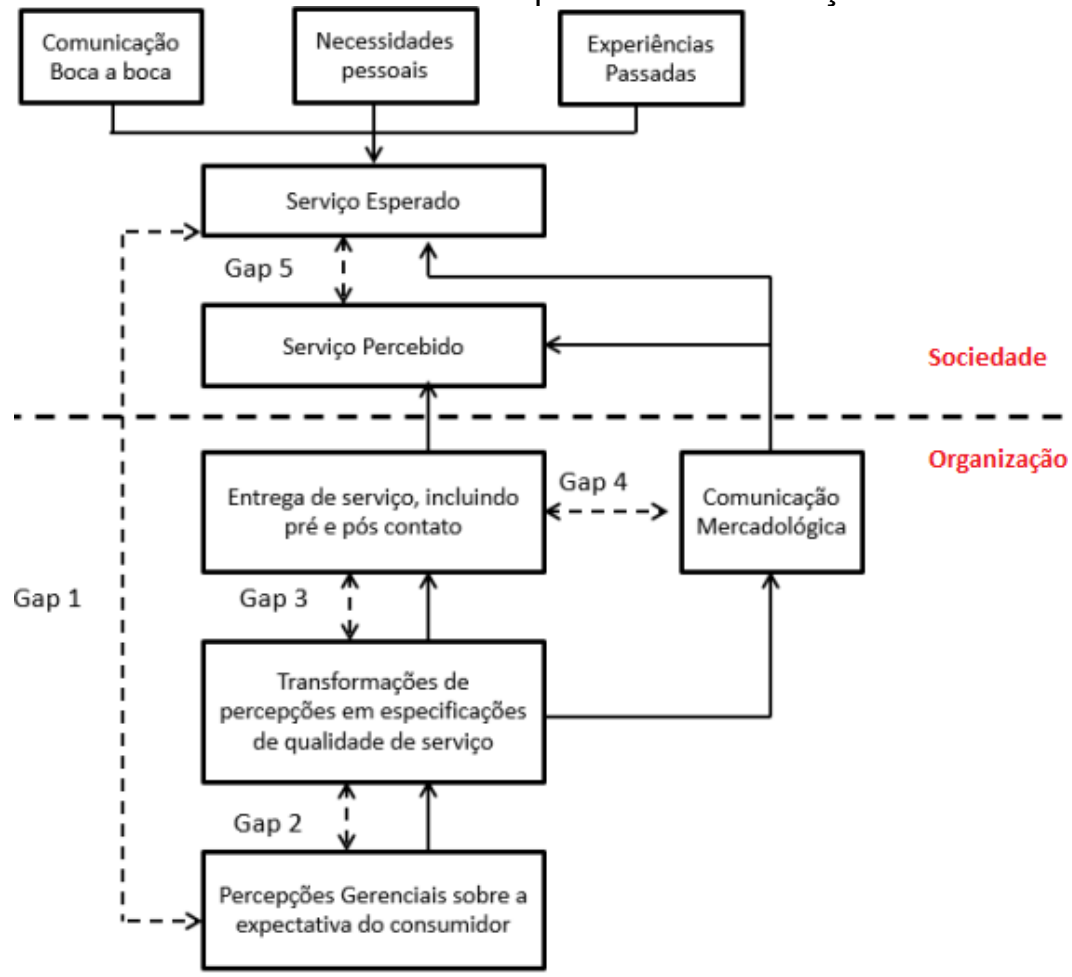

FONTE: adaptado de Zeithaml, Parasuraman e Berry (1990; 2014).

Após o encontro com o serviço, ocorre uma comparação (gap 5) entre o que se desejava antes do momento da verdade e o real desempenho. Entende-se que as lacunas podem ocorrer durante várias partes da prestação do serviço e podem ser aperfeiçoadas e desenvolvidas em uma gestão que busca alta performance.

Essas cinco lacunas expressam: Gap1: falha na comparação da expectativa dos clientes sobre o serviço e na percepção dos gestores sobre as expectativas dos clientes; Gap2: falha na comparação entre especificações da qualidade do serviço e as percepções dos gestores sobre as expectativas dos clientes; Gap3: falha entre serviço prestado e as especificações de qualidade dos 
serviços; Gap4: falha entre serviço prestado e a comunicação com os clientes; e Gap5: falha na comparação entre serviço percebido e a expectativa do serviço. Essa falha ocorre na decorrência dos gaps 1 e 4; O gap 5 é: uma medida da qualidade do serviço em relação específica a desejo $X$ realização, e, nesse contexto, envolve a esfera da instituição (gestão e estrutura organizacional) e o panorama socioambiental (comunicação boca a boca, necessidades pessoais, vivências passadas).

A avaliação da qualidade se faz subtraindo a expectativa menos percepção. $O$ evento da percepção $(P)$ deve ser maior que a expectativa (E), importa que a organização está trabalhando de maneira adequada, caso contrário (expectativa > percepção) ocorre a presença do gap.

A equação consente examinar psicrometricamente se os escores das expectativas são superiores ou inferiores aos escores das percepções da clientela em relação às dimensões que afetam a concepção da qualidade em serviços, sugerindo sinais de baixa qualidade quando a expectativa supera a percepção de alta qualidade nos casos em que a percepção é superior à expectativa declarada. Conforme o tipo de pesquisa, as assertivas que compõem o instrumento de pesquisa está estruturado em torno de uma escala de cinco ou sete pontos, que vai de concordo plenamente até discordo totalmente, sinalizando como os clientes aferem os serviços ofertados (PARASURAMAN; ZEITHAML; BERRY, 1988).

A constituição teórica, metodológica e prática Servqual pondera os hiatos da qualidade e o elemento-chave para a análise métrica é o questionário de 22 itens elaborados com questões dimensionais da qualidade em serviço.

Righi (2009) esclarece que os clientes apresentam uma ou mais expectativas a cada dimensão da qualidade em relação a um determinado serviço e comparam o serviço percebido com as suas expectativas durante e após a execução do serviço, formando um conceito único denominado qualidade perceptível do serviço.

O questionário é elaborado em duas seções: uma correspondente às expectativas, com 22 alternativas que procuram delinear as expectativas gerais do respondente em relação ao serviço a ser investigado; outra visa medir o julgamento - escala Likert de cinco pontos, variando de 'Discordo Totalmente' (1) a 'Concordo Totalmente' (5) - sobre a qualidade do serviço prestado. 
QUADRO 2 - Cinco determinantes da qualidade: assertivas, itens, fatores

\begin{tabular}{|c|c|}
\hline \multirow{4}{*}{ 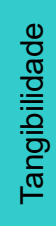 } & Equipamentos Modernos \\
\hline & Instalações visualmente agradáveis \\
\hline & Funcionários com apresentação agradável e profissional \\
\hline & Materiais associados aos serviços visualmente agradáveis \\
\hline \multirow{5}{*}{ 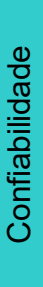 } & Serviços conforme anunciado ou prometido \\
\hline & Transmitir informações de forma confiável e precisa \\
\hline & Serviços realizados de forma correta pela primeira vez \\
\hline & Executar os serviços no tempo prometido \\
\hline & Manter os registros de forma correta \\
\hline \multirow{4}{*}{ 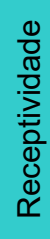 } & Clientes mantidos informados sobre quando serviços serão realizados \\
\hline & Prontidão na realização dos serviços \\
\hline & Disposição para ajudar os clientes \\
\hline & Prontidão para responder às solicitações dos clientes \\
\hline \multirow{4}{*}{ 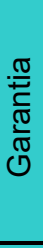 } & Funcionários que transmitem confiança ao cliente \\
\hline & Segurança transmitida ao cliente durante a compra \\
\hline & Funcionários frequentemente cordiais \\
\hline & $\begin{array}{l}\text { Funcionários com conhecimento para responder às perguntas } \\
\text { dos clientes }\end{array}$ \\
\hline \multirow{5}{*}{ 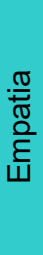 } & Clientes receberem uma atenção individual \\
\hline & Funcionários tratarem os clientes de forma atenciosa \\
\hline & Interesse genuíno demonstrado em servir o cliente \\
\hline & Funcionários que compreendem as necessidades de seus clientes \\
\hline & Horário de funcionamento conveniente aos clientes \\
\hline
\end{tabular}

FONTE: Adaptado de Zeithaml, Parasuraman e Berry (1990; 2014).

Os resultados das duas seções são então comparados para se chegar a 'resultados de lacunas' para cada uma das cinco dimensões. Quanto menor a lacuna, mais alta a expectativa de qualidade de serviços (LAS CASAS, 2017). 


\section{PROCEDIMENTOS METODOLÓGICOS}

Apresentam-se, nesta etapa, os procedimentos metodológicos referentes à construção do modelo adaptado do Servqual proposto pelos autores Abreu, Amaral e Santos (2016).

\subsection{Ambiência da pesquisa}

O estudo (do tipo survey, utilizando questionário semiestruturado para a coleta de dados) foi realizado em frente à Biblioteca Municipal Murilo Mendes (BMMM) - local próximo à Praça Antônio Carlos e ao complexo Cultural Bernardo Mascarenhas (na Avenida Getúlio Vargas, 200, centro).

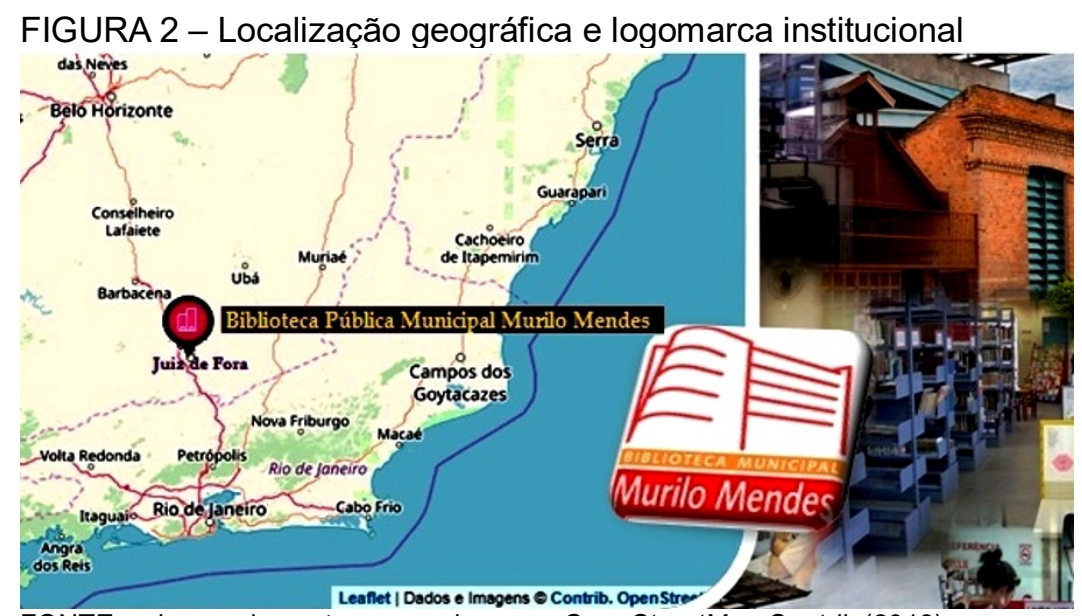

FONTE: colagem dos autores com base no OpenStreetMap Contrib (2018).

O ambiente analisado neste estudo compreende apenas a Biblioteca Municipal Murilo Mendes (sede) - o prédio em questão passou por reformas e adaptações para abrigar o acervo; no térreo abriga o Setor de Referência, Periódicos, a parte Infanto-Juvenil, sala de internet popular e hall de entrada.

\subsection{Escala de julgamento de valor e construção do questionário}

Para a coleta de dados, usam-se assertivas orientadas pela abordagem teórico-metodológica Servqual, encadeada no escalonamento Psicométrico (Escala Likert) de cinco pontos - 
mensuração simétrica com opções de julgamento - para obtenção das determinantes a serem diagnosticadas através das assertivas que posicionam o grau de expectativa e percepção, solicitando que os respondentes sugerissem uma medida de concordância ou discordância em cada um dos itens.

Neves e Vinagre (2018, p. 17) apontam que o modelo Servqual "assume uma característica importante em termos de aplicabilidade, que é a flexibilidade teórica relacionada com as dimensões da qualidade de serviço específicas de cada serviço a ser medido em relação à sua qualidade".

Conforme o tipo de estudo, as assertivas que compõem o instrumento de pesquisa podem ser estruturadas em torno de uma escala de cinco ou sete pontos, que vai de 'concordo plenamente' até 'discordo totalmente', sinalizando o contexto da 'importância' e 'satisfação' com serviços ofertados. Dessa forma, comparando-se os resultados dos dois blocos de questionamentos, haverá um parâmetro para cada uma das questões ou dimensão analisadas.

Crossno et al. (2001) afirmam que utilizar o termo 'expectativas' por 'importância' simplifica o entendimento dos itens avaliativos pelos respondentes, de igual maneira adota-se 'satisfação' na abordagem 'perceptiva' das assertivas. Dessa forma, se comparados os resultados dos dois questionamentos, haverá um parâmetro para cada uma das questões ou dimensão analisadas. Esse parâmetro é gerado devido a uma diferença entre as pontuações de cada item (Gap Model = Satisfação - Importância).

O cálculo dos gaps por determinante da qualidade é resultante da soma média das pontuações recolhidas nas assertivas de cada dimensão. Assim, o índice médio do gap do construto Garantia se dá pela média das pontuações dos itens relativos a essa esfera, e, nesse aspecto, envolve quatro itens; contudo, a quantidade de itens, em cada determinante da qualidade, pode variar conforme a adaptação métrica desse modelo.

$\mathrm{O}$ instrumento proposto para a coleta de dados arranjou-se em cinco blocos: o Bloco 1 (Perfil do respondente) visa identificar o perfil do respondente, utilizando questões quanto à idade, ao gênero, ao estado civil e à etnia. O Bloco 2 (Gap Importância) e o Bloco 3 (Gap Satisfação) buscaram mensurar as percepções e as expectativas dos itens à luz dos respondentes. O Bloco 4 (Críticas ou sugestões) proporcionou ao interagente sugerir melhorias para o aperfeiçoamento do questionário. 


\subsection{Coleta de dados e forma de análise}

Com a finalidade de verificar a clareza e adequação do questionário (autoaplicável), foi realizado um pré-teste no período de 23 a 27 de janeiro de 2017. O pré-teste é centrado na avaliação do instrumento e visa garantir que meça exatamente o que se pretende, objetivando a identificação e eliminação de problemas potenciais (GIL, 2010).

Subsequente à aplicação do pré-teste, ocorreu a lapidação e as alterações do questionário, com o objetivo de eliminar perguntas redundantes ou corrigir perguntas mal elaboradas e dúbias. A configuração do instrumento foi estruturada em torno das cinco determinantes da qualidade, ou seja, os 22 pares de questões (conforme Quadro 2) para avaliar as percepções e expectativas diante dos serviços prestados na BMMM. Assim, no que concerne à forma de análise, Magalhães (2018, p. 116) destaca:

"A qualidade é fruto da comparação entre as expectativas do cliente e a realização e o bom desempenho do serviço [...] É necessário estabelecer medidas de controle e indicadores confiáveis do desempenho dos serviços, da importância dos diferenciais e, principalmente, do grau de satisfação dos clientes".

Por meio do processo de validação e pré-testes, foi possível perceber a necessidade de ajustes dos termos 'expectativas' e 'percepções' - os quais podem, segundo Miguel (2017) e Rosemberg, Miguel e Carvalho (2018), ser 'melhor compreendidos' pelos interagentes numa instituição. Assim, com a devida, prevista e referendada inclusão dos termos 'importância' e 'satisfação'administrado em interação pessoal no pré-teste - o que aperfeiçoou o formato do questionário para captura das informações. Em seguida, realizou-se a aplicação do 'questionário' final em um período de nove semanas - de 27 de março a 27 de maio de 2017 , obtendo-se um quantitativo de 410 respostas. Para interpretação quantitativa, utilizaram-se técnicas de análise descritiva e trabalho estatístico por meio do software MS Excel.

\section{RESULTADOS E DISCUSSÃO}

Um total de 410 questionários foram aplicados em frente a biblioteca selecionada para fins deste estudo. Foram válidos os questionários que tinham a resposta "Sim" à questão: "Você já 
utilizou os serviços prestados pela BMMM". A tabela a seguir apresenta o perfil dos participantes:

\begin{tabular}{|c|c|c|c|c|c|}
\hline \multicolumn{2}{|c|}{$\begin{array}{c}\text { Característicasl } \\
\text { Perfil Social }\end{array}$} & \multicolumn{2}{|c|}{$\begin{array}{l}\text { Gênero declaradol } \\
\text { Feminino n. } 220\end{array}$} & \multicolumn{2}{|c|}{$\begin{array}{l}\text { Gênero declaradol } \\
\text { Masculino n.190 }\end{array}$} \\
\hline \multirow{3}{*}{$\begin{array}{l}\frac{\pi}{\pi} \\
\frac{\pi}{\pi} \\
\frac{\pi}{\pi}\end{array}$} & $<35$ & 154 & $70,00 \%$ & 98 & $51,58 \%$ \\
\hline & $35-65$ & 44 & $20,00 \%$ & 66 & $34,74 \%$ \\
\hline & $>65$ & 22 & $10,00 \%$ & 26 & $13,68 \%$ \\
\hline \multirow{3}{*}{ 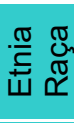 } & Branca & 160 & $72,73 \%$ & 110 & $57,89 \%$ \\
\hline & Pardo/negro & 52 & $23,64 \%$ & 76 & $40,00 \%$ \\
\hline & Outra & 8 & $3,64 \%$ & 4 & $2,11 \%$ \\
\hline \multirow{3}{*}{ 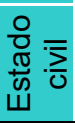 } & Solteiro & 146 & $66,36 \%$ & 106 & $55,79 \%$ \\
\hline & Casado (juntado) & 58 & $26,36 \%$ & 62 & $32,63 \%$ \\
\hline & Outro & 16 & $7,27 \%$ & 22 & $11,58 \%$ \\
\hline
\end{tabular}

FONTE: dados da pesquisa, 2017.

A validação da sondagem Servqual requer que o respondente tenha alguma experiência com o serviço para ser capaz de avaliá-lo.

No que se refere ao estado civil e faixa etária dos respondentes, a maioria, $252(61,46 \%)$, declara-se 'solteiro' e com 'menos de 35 anos'; no que tange à etnia, 270 (65,85\%) apontaram a opção 'branco'.

\subsection{Importância e satisfação}

Uma análise dos resultados permite identificar os itens mais importantes (expectativa) para a maioria dos usuários: "Instalações visualmente agradáveis" alcançaram $97,56 \%$ das respostas, e "Funcionários frequentemente cordiais" obteve 93,17\%. Ainda em relação à importância, os itens da pesquisa receberam dos respondentes uma pontuação média entre 4,44 e 4,84 de uma escala de cinco pontos. A tabela 2 apresenta a média da pontuação (na escala de 1 a 5) a respeito da importância e satisfação, agrupadas por dimensão: 


\begin{tabular}{c|c|c|c|c|c|c|c} 
TABELA 2 & Importância e Satisfação por Dimensão \\
\hline \multirow{2}{*}{ Dimensões } & \multicolumn{2}{|c|}{ Gap Importância (E) } & \multicolumn{3}{c|}{ Gap Satisfação (P) } & $(\mathrm{E})-(\mathrm{P})$ \\
& Feminino & Masculino & Média & Feminino & Masculino & Média & $\mid$ gaps| \\
\hline Empatia & 4,80 & 4,48 & 4,65 & 4,73 & 4,18 & 4,48 & 0,18 \\
\hline Garantia & 4,50 & 4,65 & 4,57 & 4,40 & 4,20 & 4,31 & 0,26 \\
\hline Receptividade & 4,70 & 4,48 & 4,60 & 4,10 & 4,20 & 4,15 & 0,45 \\
\hline Confiabilidade & 4,44 & 4,75 & 4,58 & 4,10 & 3,84 & 3,98 & 0,60 \\
\hline Tangibilidade & 4,79 & 4,84 & 4,81 & 3,90 & 4,00 & 3,95 & 0,87 \\
\hline
\end{tabular}

FONTE: dados da pesquisa, 2017.

Entre as assertivas apontadas como de "maior satisfação", a primeira delas, com $89,27 \%$ das respostas, foi "Funcionários que tratam os clientes de forma atenciosa", e o segundo, com $83,90 \%$, "Prontidão para responder às solicitações dos clientes". Ainda em relação à satisfação (percepção), os respondentes atribuíram aos itens uma pontuação média entre 3,84 e 4,48 de uma escala de cinco pontos, apontando em quatro dimensões um pequeno hiato entre a importância e a satisfação com os serviços.

Contudo, os itens que obtiveram uma pontuação menor podem caracterizar aspectos a serem aprimorados nos serviços da BMMM. Entre eles, estão "Equipamentos Modernos" e "Transmitir informações de forma confiável e precisa", ambos apresentando, respectivamente, $24,15 \%$ e $19,03 \%$ das respostas marcadas entre 'insatisfeito' e 'pouco satisfeito'. Portanto, a dimensão da qualidade do serviço apontada neste trabalho como aspectos tangíveis foi a que apresentou maior lacuna $(|0,87|)$; e como uma reflexão parece indissociada da discussão da relação gênero.

\subsection{Análises de gaps e quadrantes}

Uma forma de apresentar os resultados da pesquisa é por meio do cálculo dos gaps, o qual utiliza a seguinte fórmula: 'Gap = Satisfação - Importância'. Para cálculo das médias, as pontuações (de 1 a 5) de cada questão na respectiva dimensão são somadas e depois divididas pelo número total (410) de respondentes - obtém se, assim, a média ao fator satisfação e, paralelamente, o aspecto importância. Em seguida, calcula-se a diferença entre as duas, obtendo-se, assim, as lacunas por dimensão da qualidade; a figura 3 apresenta esses gaps: 
FIGURA 3 - Gráfico dos gaps por dimensões da qualidade

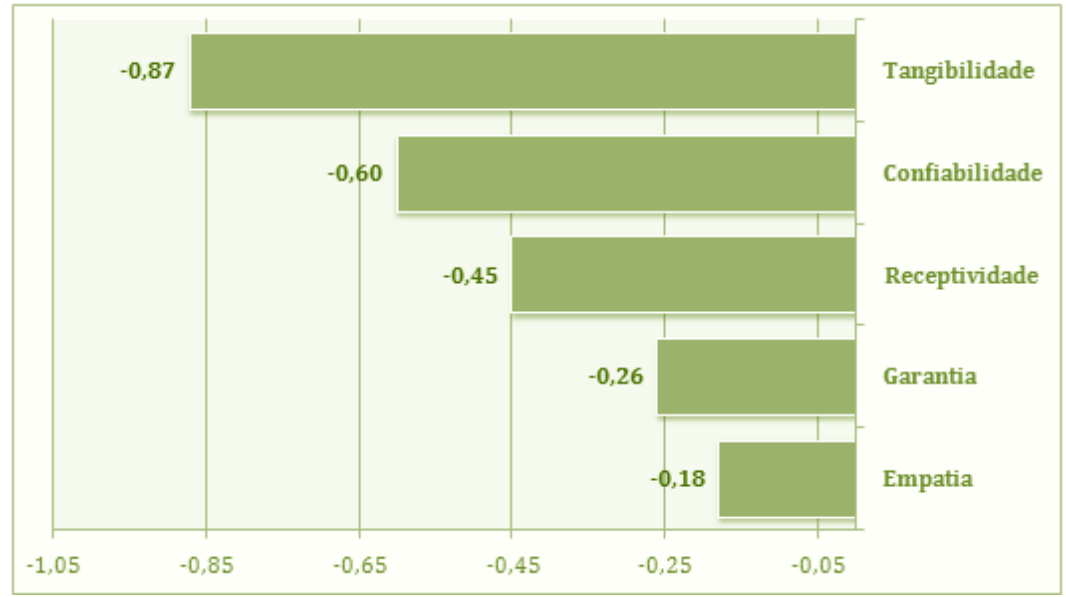

FONTE: dados da pesquisa (2017).

Averigua-se, pela figura acima, que os hiatos entre o serviço desejado e o de fato encontrado abrangem os aspectos tangíveis da BMMM. Ao que tudo indica, essa lacuna demonstra que a atratividade das instalações físicas é um ponto crítico para a qualidade do serviço, pois influencia não apenas a percepção da ambiência, mas também as expectativas que remete ao sentido de 'lazer e bem-estar' apontados pelos respondentes. Não obstante, é importante destacar que as pontuações de gaps entre 0 e -1 não superam as expectativas, no entanto podem atender a um tipo de serviço 'padrão' (NITECKI; HERNON, 2000).

Já a Análise de Quadrante (Matriz Importância \& Desempenho) é apontada por Nitecki e Hernon (2000) como uma importante correlação gráfica que facilita a visualização das informações; abrange um instrumento capaz de posicionar ações organizacionais para os seguintes aspectos: manter, aperfeiçoar, realocar recursos, rever esforços. No presente estudo, verifica-se uma concentração no quadrante 1 (manter) de todos os vinte e dois atributos da qualidade (Figura 4). 
FIGURA 4 - Análise de Quadrantes

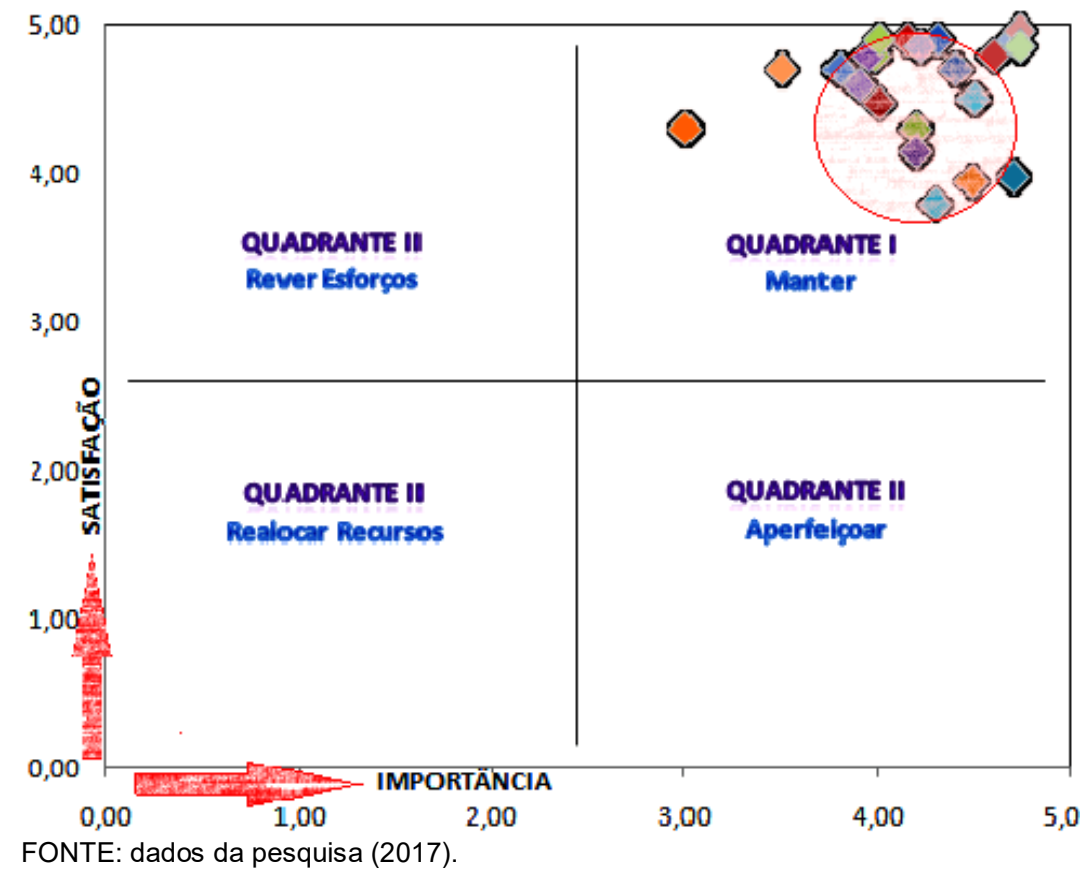

Tal concentração no 'quadrante I' indica que os respondentes veem os atributos como sendo altamente importantes e bem executados pela BMMM. A análise dessa matriz se constrói em uma análise bidimensional, em que a importância corresponde à abscissa (eixo horizontal $\mathrm{x}$ ) e se atribui à ordenada (coordenada vertical y) a satisfação. Assim, um atributo que se situar no Quadrante I estará posicionado em termos de alta importância com alto desempenho representando uma possível vantagem organizacional.

\section{CONSIDERAÇÕES E RECOMENDAÇÕES}

Conforme a $5^{\mathrm{a}}$ Lei de Ranganathan (2009), a 'biblioteca é um organismo em crescimento', e, portanto, deve acompanhar as mudanças que ocorrem a todo momento na sociedade, buscando formas de cumprir sua missão institucional. Assim sendo, o objetivo deste trabalho pautou-se na averiguação da qualidade dos serviços prestados pela BMMM, enfocando a satisfação e importância da qualidade dos serviços de uma biblioteca pública pela ótica da 
comunidade usuária. Em suma, testar e validar o instrumento Servqual para mensurar a qualidade de serviços prestados.

Em termos gerais, os resultados apontam que o instrumento Servqual é uma ferramenta que concilia boas propriedades psicométricas, ou seja, traz à tona um diagnóstico válido e confiável sobre a qualidade dos serviços no âmbito da instituição pesquisada.

Essa abordagem métrica surgiu para quantificar a satisfação dos clientes em relação à prestação de serviços, solicitando aos múltiplos interagentes em um determinado local ou evento que avaliassem os serviços prestados, dimensionando-se, assim, as percepções e as expectativas quanto à qualidade e o desempenho institucional. Esse parâmetro determina a forma pela qual o respondente avalia a qualidade do serviço, na consideração de que a clientela possui uma expectativa sobre a qualidade do serviço, com base em suas necessidades e experiências já vividas.

Usar estrategicamente a métrica Servqual e as informações do diagnóstico acarreta elevar a gestão e a aplicação de recursos da instituição, portanto, agrega valor ao produto e/ou serviços ofertados. Além disso, a capacidade de adaptação e ampliação da ferramenta Servqual para a realidade da organização que a utilizará é uma vantagem evidenciada pelos próprios autores Parasuraman, Zeithaml e Berry (1988).

Nesta pesquisa, os resultados indicam uma lacuna clara nos aspectos tangíveis, alcançado em termos médios $|0,87|$ de discrepância; configura-se, assim, um problema de pesquisa passível à ambiência física da instituição, compreendendo poucos investimentos nos acervos, mobiliários, rede tecnológica, demais equipamentos que possam sinalizar a modernidade da instituição. A dimensão tangibilidade designa "as instalações e todos os outros aspectos físicos, como equipamentos, pessoas e material de comunicação" (MAGALHÃES, 2018, p. 94).

Nesse panorama de gaps por dimensões, há uma contestação de um hiato entre o serviço desejado e o encontrado a dimensão empática apresenta o menor índice dissentido. Isso indica que, apesar do 'horário de funcionamento' (última questão do questionário aplicado) não ser conveniente a todos, isso não afeta a assertiva que remete à questão 'funcionários compreendem as necessidades de seus clientes' - o que ratifica o âmbito do cuidado com a comunidade.

Faz-se necessário analisar com reserva os resultados do diagnóstico particular, baseados em amostra de conveniência. Convém ressaltar que a 'amostragem teórica' compreende a uma 
conjectura em que os dados são coletados, decodificados e analisados de forma sistemática e simultânea até a saturação teórica, ou até que dados novos ou relevantes não sejam mais achados ou que se comece a se repetir. Destarte, o recorte amostral adotado neste estudo garante uma amplitude de ações, no que tange a aspectos particulares apenas a entidade bibliotecária pesquisada.

Algumas limitações foram encontradas no decorrer da execução deste estudo e se faz necessário considerá-las e descrevê-las. Assim, não é viável fazer inferências generalizantes sobre a qualidade dos serviços institucionais, o que se torna uma limitação - diante do território interdisciplinar da Ciência da Informação e o vasto e profícuo território das 6057 bibliotecas públicas no Brasil (SNBP, 2015). Por fim, a dificuldade de encontrar literatura que aborde qualidade na prestação de informacionais específicos a bibliotecas públicas, obrigando a utilização, em sua maioria, de vislumbrar comparativamente os espaços das bibliotecas universitárias.

Recebido em: 02 jun.2017 Aceito em: 12 fev. 2019

\section{REFERÊNCIAS}

ABREU, L. G. B.; AMARAL, V. F.; SANTOS, A. C. S. G. Uma adaptação do modelo Servqual para mensuração da qualidade de serviços internos sob a perspectiva dos colaboradores: um estudo de caso em uma Instituição de Ensino Federal. In: XIX Simpósio de Administração de Produção, Logística e Operações Internacionais, São Paulo. Anais.. São Paulo: FGV: SIMPOI, 2016.

BERNARDINO, M.; SUAIDEN, E. Imagem da biblioteca pública na Sociedade da Informação. InCID: Revista de Ciência da Informação e Documentação, v. 2, n. 1, p. 130-142, jun. 2011. Disponível em: <www.revistas.usp.br/incid/article/view/42338/46009>. Acesso em: 29 nov. 2018.

CALDAS, R. F.; SILVA, R. C. Bibliotecas Vivas e Inclusão Informacional: uma Perspectiva para o Uso do Design da Informação na Inclusão Social em Espaços Informacionais Híbridos. Perspectivas em Gestão \& Conhecimento, v. 6, n. N. Especial, p. 230-239, 2016.

CAMPOS, A. C. B.; MIGUEL, M. C.; CARVALHO, S. M. S. Aplicação do modelo Servqual na bienal do livro da Zona da Mata: o olhar dos interagentes abrindo novas páginas para melhoria da qualidade. Encontros Bibli, Florianópolis, v. 23, n. 52, p. 84-94, maio 2018. ISSN 1518-2924. Disponível em: < https://doi.org/10.5007/1518-2924.2017v23n52p84>. 
Acesso em: 02 fev. 2019. doi:

CORREAA, E. C. D. Usuário, não! Interagente. Proposta de um novo termo para um novo tempo. Encontros Bibli: revista eletrônica de biblioteconomia e ciência da informação, Florianópolis, v. 19, n. 41, p. 2340, dez. 2014. ISSN 1518-2924. Disponível em: <https://doi.org/10.5007/15182924.2014v19n41p23.>. Acesso em: 16 dez. 2018.

CROSSNO, J. E. et al. Assessment of customer service in Academic Health Care Libraries (ACSAHL): an instrument for measuring customer service. Bulletin of the Medical Library Association, v. 89, n. 2, pp. 170-176, Abr. 2001. Disponível em: <http://www.ncbi.nlm.nih. gov/pmc/articles/PMC31724/>. Acesso em: 17 mar. 2015.

FITZSIMMONS, J.; FITZSIMMONS, M. Administração de serviços: operações, estratégia e tecnologia de informação. 2. ed. Porto Alegre: Bookman, 2010.

GIL, A. C. Como elaborar projetos de pesquisa. 5. ed. São Paulo: Atlas, 2010. $184 \mathrm{p}$.

GRÖNROOS, C. A service quality model and its marketing implications. European Journal of Marketing. v. 18, n. 4, p. 36-44, 1984

Elsevier, 2003.

IFLA/UNESCO. Manifesto da IFLA/Unesco sobre Bibliotecas Públicas. IFLA, 1994. Disponível em: <http://snbp.culturadigital.br/manifestos/manifestoda-unesco-sobre-bibliotecas-publicas/>. Acesso em: 22 abr. 2016.

LAS CASAS, A. L. Qualidade total em serviços: conceitos, exercícios, casos práticos. 6. ed São Paulo: Atlas, 2017. 223 p.

MAGALHÃES, M. F. Qualidade na prestação de serviços: agregando valor às organizações. São Paulo: Senac São Paulo, 2018. 200 p.

MENDES, M. Murilo Mendes: poesia completa e prosa. Rio de Janeiro: Nova Aguilar, 1994.

MIGUEL, M. C. Múltiplos olhares em prol da qualidade de serviços biblioteconômicos. Revista ACB, [S.I.], v. 22, n. 2 ESPECIAL, p. 192-207, jul. 2017. ISSN 1414-0594. Disponível em: <https://revista.acbsc.org.br/racb/article/view/1312>. Acesso em: 18 out. 2018.

NEVES, J. G.; VINAGRE, M. H. Qualidade de Serviço, diagnosticar para Intervir: O Gap Model. Lisboa: Sílabo, 2018.

NITECKI, D. A.; HERNON, P. Measuring service quality at Yale's University's libraries. The Journal of Academic Librarianship, Ann Arbor, v. 26, n. 4, p. 259-273, Jul. 2000.

PARASURAMAN, A; ZEITHAML, V. A; BERRY, L. L. A conceptual model of service quality and its implications for future research. Journal of Marketing, Chicago, v. 49, n. 4, p. 41-50, 1985. 
;;

Servqual: a multiple-item scale for measuring consumer perceptions of service quality. Journal of Retailing, v. 64, p. 12-40, 1988.

PRIMO, A. F. T.; CASSOL, M. B. F. Explorando o conceito de Interatividade: definições e taxonomias. Informática na Educação: teoria \& prática. Porto Alegre, v. 2, n. 2, p. 65-80, 1999.

RANGANATHAN, S. R. As cinco leis da biblioteconomia. Brasília: Briquet de Lemos, 2009. XXV, 336 p.

RIGHI, A. W. Avaliação da qualidade em serviços públicos de saúde: o caso da estratégia saúde da família. Tese de Mestrado em Engenharia de Produção - Universidade Federal de Santa Maria, 2009. Disponível em <https://repositorio.ufsm.br/bitstream/handle/1/8109/RIGHI\%2C\%20ANGEL A\%20WEBER.pdf> Acesso em 31 Ago. 2017.

ROSEMBERG, D. S.; MIGUEL, M. C.; CARVALHO, S. M. S. Qualidade Percebida $\mathrm{Na}$ Ótica Do Usuário: emprego da abordagem teóricometodológica Servqual em um serviço de referência. PontodeAcesso, v. 12, n. 2, p. 40-57, out. 2018. Disponível em: <https://portalseer.ufba.br/index.php/revistaici/article/view/16740>. Acesso em: 30 nov. 2018.

SALDANHA, G.; PEREIRA, R. Das Políticas do Prazer: o lazer no pensamento biblioteconômico-informacional e sua dimensão aplicada na institucionalidade das bibliotecas. Revista de Ciência da Informação e Documentação, v. 7, n. 1, p. 5-28, abr. 2016. Disponível em: <https://www.revistas.usp.br/incid/article/view/109696>. Acesso em: 11 nov. 2017.

SANTOS, J. M. A cultura da informação nas bibliotecas públicas brasileiras. Revista Brasileira de Biblioteconomia e Documentação. São Paulo, v. 10, n. 1, p. 54-67, jan./jun. 2014. Disponível em: <https://rbbd.febab.org.br/rbbd/article/view/280/291>. Acesso em: 29 nov. 2016.

SILVEIRA, F. Biblioteca Pública Estadual de Minas Gerais: percurso histórico e dinâmicas de inserção social. InCID: Revista de Ciência da Informação e Documentação, v. 9, n. 1, p. 146-167, 1 jun. 2018. Disponível em: <www.revistas.usp.br/incid/article/view/138665>. Acesso em: 29 nov. 2018.

SISTEMA NACIONAL DE BIBLIOTECAS PÚBLICAS: SNBP. Informações Das Bibliotecas Públicas, Brasília, 2015. Disponível em: <http://snbp.cultura.gov.br/bibliotecaspublicas/>. Acesso em: 11 set. 2018.

TOMAÉL, M. I. et al. A contribuição do processo de inteligência competitiva para a inovação nas organizações. In: VALENTIM, M. L. P. (Org.). Informação, conhecimento e inteligência organizacional. Marília: FUNDEPE, 2006. 282 p. 155-175 
TRZECIAK, D. S. Modelo de observatório para arranjos produtivos locais. 2009. 234f. Tese (Doutorado em Engenharia de Produção) Programa de Pós Graduação em Engenharia de Produção, Universidade Federal de Santa Catarina, Florianópolis, 2009.

ZEITHAML, V. A; PARASURAMAN, A; BERRY L. L. Delivering Quality Service: Balancing Costumer Perception and Expectation. New York: The Free Press, 1990. ; A excelência em serviços: como superar as expectativas e garantir a satisfação completa de seus clientes. São Paulo: Saraiva, 2014. 